\title{
Clostridium difficile is not associated with outbreaks of viral gastroenteritis in the elderly in the Netherlands
}

\author{
S. Svraka • E. Kuijper • E. Duizer • D. Bakker • \\ M. Koopmans
}

Received: 8 September 2009 / Accepted: 8 March 2010 /Published online: 27 March 2010

(C) The Author(s) 2010. This article is published with open access at Springerlink.com

\begin{abstract}
The coincidental increase in norovirus outbreaks and Clostridium difficile infection (CDI) raised the question of whether these events could be related, e.g. by enhancing spread by diarrhoeal disease outbreaks. Therefore, we studied the prevalence of $C$. difficile in outbreaks of viral gastroenteritis in nursing homes for the elderly and characterised enzyme immunoassay (EIA)-positive stool samples. Stool samples from nursing home residents $(n=752)$ in 137 outbreaks of viral aetiology were investigated by EIA for the presence of $C$. difficile toxins. Positive samples were further tested by a cell neutralisation cytotoxicity test, a second EIA and culture. Cultured isolates were tested for the presence of toxin genes, the production of toxins and characterised by 16S rRNA polymerase chain reaction (PCR) and sequencing. Twenty-four samples (3.2\%) tested positive in the EIA. Of these 24 positive samples, only two were positive by cytotoxicity and three by a second EIA. Bacterial culture of 21 available stool samples yielded a toxinogenic $C$. difficile PCR ribotype 001 in one patient sample only. In conclusion, we found no evidence in this retrospective study for an
\end{abstract}

\footnotetext{
S. Svraka $(\bowtie) \cdot$ E. Duizer $\cdot$ M. Koopmans $(\bowtie)$

Laboratory for Infectious Diseases and Perinatal Screening, Center for Infectious Disease Control,

National Institute for Public Health and the Environment,

P.O. Box 1, 3720 BA Bilthoven, The Netherlands

e-mail: s.svraka@gmail.com

e-mail: Marion.Koopmans@rivm.nl

E. Kuijper · D. Bakker

Department of Medical Microbiology,

Leiden University Medical Center,

Leiden, The Netherlands

M. Koopmans

Erasmus Medical Center,

Rotterdam, The Netherlands
}

association between viral gastroenteritis outbreaks and C. difficile. The high rate of false-positive EIA samples emphasises the need for second confirmation tests to diagnose CDI.

\section{Introduction}

Outbreaks of acute gastroenteritis (AGE) of suspected viral aetiology are reported to the National Institute for Public Health and the Environment (RIVM) as part of the ongoing viral gastroenteritis outbreak surveillance system. Although these outbreaks are selected based on criteria thought to be highly specific for viral gastroenteritis outbreaks, and despite extensive testing, the cause of approximately $12 \%$ of outbreaks of AGE remains unknown [1]. Of the outbreaks in which a viral pathogen was detected, the vast majority is associated with noroviruses (NoV).

Since 2002, the epidemiology of NoV appears to have changed, with the introduction of a novel lineage of the dominant genogroup (G) II.4 viruses. This introduction coincided with increased levels of reporting of $\mathrm{NoV}$ outbreaks across Europe and a noticeable peak in mortality in the elderly, which coincides with the NoV seasonal peak [2]. Simultaneously, Canada, the USA and, later, the United Kingdom (UK), the Netherlands, Belgium, France and Austria reported the emergence of Clostridium difficile ribotype 027 , which appeared to have increased virulence compared to other $C$. difficile strains [3, 4]. In the Netherlands, this ribotype was detected in 26 hospitals and ten nursing homes by May 2008 [5, 6]. Antibiotic use has been associated with an increased risk of infection with C. difficile and is responsible for 15 to $25 \%$ of all cases of antibiotic-associated diarrhoea in hospitals [7]. Outbreaks and cases outside hospitals are less frequently recognised 
but have been described, sometimes without the typical risk factors $[8,9]$. C. difficile outbreaks and cases in nursing homes have been studied less systematically and, although C. difficile type 027 has been found in at least ten nursing homes in the Netherlands, detailed information about these infections is absent [6].

The coincidental increase in norovirus GII.4 outbreaks and the spread of $C$. difficile ribotype 027 raised the question of whether these events could be related $[2,10]$. In theory, mixed infections of $\mathrm{NoV}$ and $C$. difficile ribotype 027 could increase the severity of the disease. Furthermore, norovirus-induced episodes of vomiting and diarrhoea might trigger or exacerbate $C$. difficile diarrhoea, resulting in increased spread of $C$. difficile due to multiple episodes of vomiting and diarrhoea, as has been suggested in some recent publications [11-13]. Therefore, we decided to investigate a possible association of norovirus and rotavirus outbreaks with $C$. difficile infections (CDIs), particularly with respect to $C$. difficile polymerase chain reaction (PCR) ribotype 027 .

\section{Materials and methods}

\section{Sample collection}

In total, we tested 752 faecal samples from 137 outbreaks of gastroenteritis (number of stool samples varying from 2 to 25 per outbreak). All outbreaks occurred in 2006 in nursing homes and were selected because the $C$. difficile ribotype 027 problem emerged in that period in the Netherlands and these samples provided a snapshot of what is present within the elderly population. Viral detection has been performed as described previously by Svraka et al. [1]. The outbreaks were first tested using the assays for NoV. Then, all outbreaks that remained negative were further tested using the assays for rotaviruses, adenoviruses, astroviruses and sapoviruses [1]. Of these, 109 were confirmed norovirus outbreaks (644 stool samples), 14 outbreaks were confirmed rotavirus outbreaks (70 samples) and 14 outbreaks (38 samples) were of unexplained aetiology, reflecting the typical aetiology of such outbreaks. The outbreaks were reported throughout the year, but with a peak in winter, as part of our ongoing surveillance for viral gastroenteritis outbreaks, which explains the high number of NoV outbreaks in this study [1]. Undiluted stool samples had been stored at $4{ }^{\circ} \mathrm{C}$, as recommended for viral gastroenteritis diarrhoea, before testing for the presence of $C$. difficile.

Diagnostic assays used for the screening of samples

The screening of 752 outbreak specimens for the presence of C. difficile was done using the PTAB enzyme immunoassay
(EIA, Premier $C$. difficile Toxin A\&B, Meridian Diagnostics, Inc., Cincinnati, OH, USA) on all stool samples. Assay was performed as described by the manufacturer. The stool samples had been stored at $4^{\circ} \mathrm{C}$ for periods longer than 3 4 days, which is in accordance with recommendations for the diagnostics of viral gastroenteritis, but not in accordance to the manufacturer's recommendations, before testing for the presence of $C$. difficile. Consequently, we validated the PTAB EIA assay for use in samples that were stored longer at $4^{\circ} \mathrm{C}$ by the parallel testing of 96 stool samples that were aliquoted directly after receipt and stored for five months at -20 and $4^{\circ} \mathrm{C}$.

The PTAB EIA was interpreted visually (within $15 \mathrm{~min}$ ) and by spectrophotometer (within $30 \mathrm{~min}$ ), as described by the manufacturer; 376 samples were read both visually and on a Labsystems Multiskan RC spectrophotometer plate reader (Thermo Fisher Scientific, Breda, the Netherlands) using dual wavelengths of 450 and $450 / 630 \mathrm{~nm}$. The samples were described as positive if optical density (OD) values of 0.100 or more were measured at a wavelength of $450 / 630 \mathrm{~nm}$ and/or 0.150 or more at a wavelength of $450 \mathrm{~nm}$, as described by the manufacturer. There was $100 \%$ concordance between reading visually and by using the spectrophotometer plate reader. The remaining 376 samples were read visually only.

\section{Confirmatory testing on PTAB-positive samples}

Stool samples found positive using the PTAB EIA assay were cultured and tested using a neutralisation cytotoxicity assay and the automated immunoanalyzer VIDAS ${ }^{\circledR} C$. difficile A \& B (bioMérieux) [14].

For culture, stool samples found positive in the PTAB EIA assay were treated with absolute ethanol (96\%) prior to inoculation onto Columbia agar containing colistin and nalidixic acid, $C$. difficile-selective agar with cefoxitin, amphotericin $\mathrm{B}$ and cycloserine (CLO; bioMérieux) and blood agar. CLO medium was also used to inoculate faecal samples without pre-treatment with ethanol. Inoculated faecal samples were incubated in an anaerobic environment at $37^{\circ} \mathrm{C}$ for 2 days.

Clostridium-suspected colonies were tested further using PCR assays for $C$. difficile-specific GluD targeting the GDH gene [15], $C$. difficile ribotyping [16, 17], enterotoxin A (tcdA) [5], cytotoxin B (tcdB) [18] and 16S rRNA PCR [19]. For this, DNA was isolated from suspected colonies by a QIAamp DNA isolation column (Qiagen, Holden, Germany) according to the manufacturer's recommendations, including $10 \mathrm{~min}$ incubation at $55^{\circ} \mathrm{C}$ with proteinase $\mathrm{K}$. The final volume of the DNA extracts was $200 \mu \mathrm{L}$.

The neutralisation cytotoxicity assay was performed using Vero cells in a 24-well format. Faecal samples were diluted in 1:4 Eagle's minimum essential medium (EMEM) 
containing 5\% foetal bovine serum and centrifuged for $10 \mathrm{~min}$ at 3,000 rpm. The supernatant was filtered through a $0.45-\mu \mathrm{m}$-pore filter, $150 \mu \mathrm{L}$ supernatant was mixed with $150 \mu \mathrm{l}$ EMEM and neutralisation of the cytotoxic effect was performed using $150 \mu \mathrm{L}$ faecal supernatant and $150 \mu \mathrm{l}$ of 1:25 dilution of specific $C$. difficile antitoxin (Techlab, Blacksburg, VA, USA). These two mixtures were incubated for $30 \mathrm{~min}$ at room temperature; subsequently, $200 \mu \mathrm{l}$ of each mix was inoculated on Vero cells. The cytotoxic effect was evaluated daily for 3 days microscopically.

Stool samples positive in the PTAB EIA were also tested using the VIDAS assay. Stool samples were centrifuged for $10 \mathrm{~min}$ at maximum speed $(14,000 \mathrm{rpm})$ and $300 \mu \mathrm{l}$ of supernatant was used, according to the manufacturer's instructions. Samples with OD value lower than 0.13 were described as negative, OD values between 0.13 and 0.37 were equivocal and $\mathrm{OD}$ values higher than 0.37 were described as positive.

Bacterial isolates cultured from EIA-positive faeces samples were also investigated for the production of tcdA and tcdB by VIDAS and EIA. Bacteria were cultured in liquid brain heart infusion (BHI) bouillon medium for 4 days. Subsequently, the BHI cultures were centrifuged at $3,000 \mathrm{rpm}$ for $10 \mathrm{~min}$ and the supernatant was further investigated. The same cut-off values of EIA and VIDAS were used for in vitro bacterial toxin production as for toxin detection in faeces samples.

\section{Evaluation of the approach of Clostridium detection}

Optimal sample storage conditions differ for viral testing and bacterial testing, and this raised the question whether Clostridium EIA test results could be explained by suboptimal use of the assay. Therefore, we validated this approach by testing original total nucleic acids isolated from $154(20 \%$ of all samples tested in the EIA) faecal samples within 3 days of arrival from the stool samples which were included in our study. These extracts had been stored at $-80^{\circ} \mathrm{C}$. We used a real-time PCR for the tcdB gene, as described by van den Berg et al. [14, 20]

\section{Results}

Testing of stool samples using the PTAB EIA

For the validation of the use of the PTAB EIA on our sample set, we used 96 stool samples that were stored for 5 months at -20 and at $4{ }^{\circ} \mathrm{C}$. Of the samples stored at $-20^{\circ} \mathrm{C}$, two were positive, and of the samples stored at $4^{\circ} \mathrm{C}$, three were positive, including the ones that were positive after storage at $-20^{\circ} \mathrm{C}$.

In total, $24(3.2 \%)$ of 752 stool samples from outbreaks of acute gastroenteritis in nursing homes in 2006 tested positive in the PTAB EIA assay (Table 1). Of the 24 PTAB EIA-positive stool samples, 22 were from 17 norovirus outbreaks, one was from a rotavirus outbreak and the other one was from an outbreak of unexplained aetiology.

\section{Confirmatory testing of PTAB-positive stool samples}

Specialised stool culture for Clostridium spp. (Table 1) was performed on 24 stool samples. For three stool samples, culture was negative, and in 21 stool samples, Clostridiumsuspected colonies were found. Subsequently, neutralisation cytotoxicity assay and VIDAS assay were performed on 21 stool specimens of which sufficient amounts of material were available. This yielded two positive samples both by neutralisation cytotoxicity assay and VIDAS, and an additional weakly positive result using the VIDAS assay (Table 1).

Analysis of bacterial isolates from the stool samples

From the 21 Clostridium-suspected colonies, which were grown on the CLO medium plates, DNA was extracted and analysed by 16S DNA sequencing and further using a range of assays for the characterisation of toxin-producing C. difficile (Table 1). 16S DNA sequencing revealed Lactobacilli in six stool samples $(37.5 \%)$ and different Clostridium species in 15 samples (62.5\%): C. difficile, C. disporicum, C. perfringens, C. sordellii, C. boltei, C. butyricum, C. baratii, C. subterminale and C. bifermentans (Table 1). Using the GluD, ribotyping PCR, tcdA and tcdB assays, one sample was positive and identified as C. difficile. One isolate of $C$. disporicum was weakly positive for tcdA and one isolate of $C$. subterminale for tcdB.

One Clostridium species from a faecal sample (13/8, Table 1) tested positive by EIA, cytotoxicity and VIDAS was identified as $C$. sordellii. This isolate was negative for tcdA and tcdB and did not produce a cytotoxin.

The results of the in vitro bacterial toxin production measured by cytotoxicity, PTAB and VIDAS revealed only strongly positive results for one sample that was identified as C. difficile. Using cut-off values of PTAB and VIDAS as applied on stool samples, (weakly) positive reactions were obtained for 14 samples using PTAB and six samples using the VIDAS assay. However, none of these isolates produced cytotoxins.

Epidemiological data on C. difficile- and C. sordellii-positive samples

Only one stool sample and the corresponding bacterial isolate were positive in all assays and proven to be $C$. difficile type 001 (23/18, Table 1). This sample was from an outbreak of unexplained aetiology that occurred in November 2006, with eight cases being reported. All eight samples were tested 


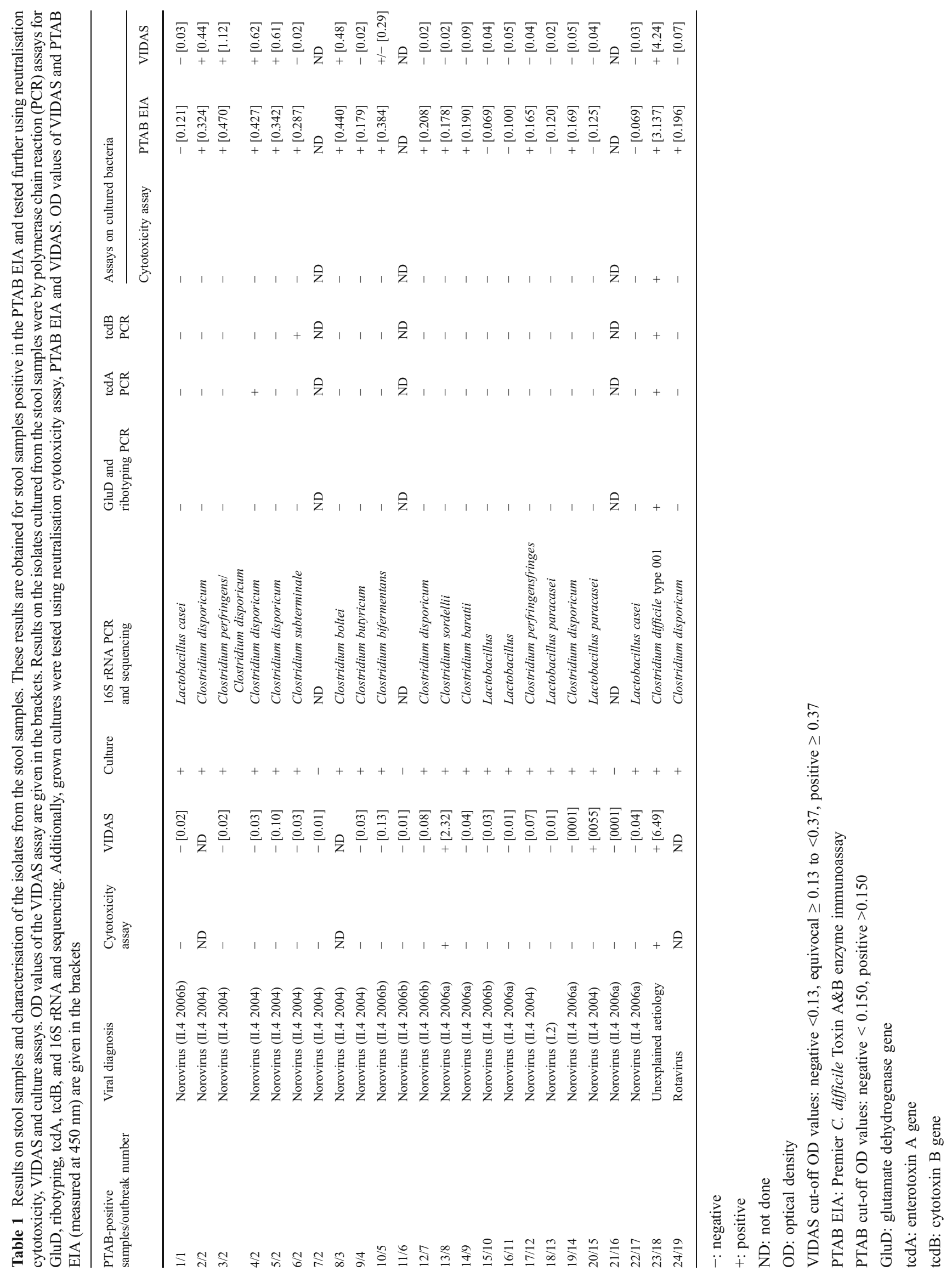


using the PTAB EIA; however, only one was positive and tested further in other assays.

The $C$. sordellii-positive stool sample (13/8, Table 1$)$ was from a norovirus outbreak that affected four persons from a residential institution in an endemic region for $C$. difficile in November 2006. The faeces samples of the three other patients were tested for CDI, but were negative.

\section{Evaluation of the approach of Clostridium detection}

Of the 154 total nucleic acids that had been isolated from stool samples within 3 days of their arrival, the two samples that were cytotoxic and VIDAS-positive were positive by tcdB real-time PCR assay (Table 1 samples 13/8 and 23/18). All other samples were negative.

\section{Discussion}

In this study, we investigated whether the emergence of a successful norovirus strain [10] could coincide with the spread of $C$. difficile and whether the emergence of C. difficile could explain some unresolved outbreaks of acute gastroenteritis in nursing homes, as has been postulated. This was initiated by publications suggesting that such an association may exist [11-13, 21]. We did not find any evidence for such an association in our retrospective study. C. difficile PCR ribotype 001 was found in a single patient in one gastroenteritis outbreak of unexplained aetiology in a nursing home. This type is one of the most frequently circulating and detected types in the Netherlands.

However, our study was performed on outbreaks in nursing homes, while other studies describe hospital outbreaks, where CDIs are more common [3-5]. Wilcox and Fawley have shown that CDI rates are higher in closed hospital units which are affected by viral gastroenteritis than in open units where no viral gastroenteritis was detected [11]. Their results were not confirmed using $C$. difficile-specific assays, and our data suggest that falsepositivity may explain previously noted associations between norovirus and Clostridium. We were unable to confirm the presence of $C$. difficile in all but one PTAB EIA-positive stool. This is not explained by their inability to culture, because other Clostridium species were isolated from $63.3 \%$ of all reactive samples.

Our study does have some limitations: first, stool samples had been sent by regular mail and stored at $4^{\circ} \mathrm{C}$ with a maximum of 16 months. This is in accordance with recommendations for the diagnostics of viral gastroenteritis, but is unusual for CDI tests. We did, however, find that the sensitivity of the PTAB EIA was not affected by storage of 5 months at $4{ }^{\circ} \mathrm{C}$ relative to storage at $-20^{\circ} \mathrm{C}$. Furthermore, the testing of original total nucleic acids isolated from faecal samples within 3 days of arrival yielded the same positives as the combination of cytotoxicity test and VIDAS. Therefore, we conclude that our findings are not due to the degradation of $C$. difficile toxins [22, 23].

In addition, this was a retrospective study and stool samples were selected from patients with a suspected viral gastroenteritis [24]. Criteria for viral gastroenteritis differ from those for Clostridium gastroenteritis, since symptoms for CDIs are highly variable, ranging from mild diarrhoea to life-threatening colitis, and including watery diarrhoea [25].

Bignardi et al. noted that, if a large number of stool specimens are submitted for the testing of the prevalence of C. difficile during norovirus outbreaks, it is likely that the number of false-positive results will increase [12]. The Clostridium species found in this study, such as C. disporicum, C. perfringens, C. sordellii, C. boltei, C. butyricum, C. baratii, C. subterminale and C. bifermentans, are bacteria that are commonly found in the gut. These bacterial isolates did react weakly positive, using the cut-off values for the faecal material, by $C$. difficile PTAB EIA, confirming the specificity problem on stool samples stored for a long period at $4^{\circ} \mathrm{C}$ [26-31]. The PTAB EIA has a positive predictive value (PPV) of $87.4 \%$ according to the manufacturer's assessment when tested according to the manufacturer's recommendations. A prospective multicentre study using the cytotoxicity assay as a gold standard revealed a PPV value of $50.9 \%$ and a specificity of $94.3 \%$, indicating that this assay is not highly specific when used for broader testing [14]. A recently performed meta-analysis by the European Study Group on Clostridium difficile (ESGCD) confirmed the PTAB to have an unacceptably low PPV of $50 \%$ at a prevalence rate of $5 \%[32]$.

A possible explanation for the high rate of false-positive PTAB results could be that suboptimal sample storage influenced the tests with weakly positive results just near to the cut-off values. Unfortunately, we were unable to test this hypothesis by a comparison of OD values of the false-positive samples with OD values of CDI-confirmed samples. Nonetheless, we recommend additional confirmatory testing, preferably a cell neutralisation cytotoxicity assay, which is the reference testing method for detection, or a molecular detection test including typing, specifically when samples are not sent in and stored according to $C$. difficile diagnostic criteria.

In summary, we found no evidence for an association between the spread of norovirus and $C$. difficile. Previous reports that suggested this association may be explained by false-positive PTAB tests.

Open Access This article is distributed under the terms of the Creative Commons Attribution Noncommercial License which permits any noncommercial use, distribution, and reproduction in any medium, provided the original author(s) and source are credited. 


\section{References}

1. Svraka S, Duizer E, Vennema H, de Bruin E, van der Veer B, Dorresteijn B, Koopmans M (2007) Etiological role of viruses in outbreaks of acute gastroenteritis in The Netherlands from 1994 through 2005. J Clin Microbiol 45(5):1389-1394

2. Lopman B, Vennema H, Kohli E, Pothier P, Sanchez A, Negredo A, Buesa J, Schreier E, Reacher M, Brown D, Gray J, Iturriza M, Gallimore C, Bottiger B, Hedlund KO, Torvén M, von Bonsdorff CH, Maunula L, Poljsak-Prijatelj M, Zimsek J, Reuter G, Szücs G, Melegh B, Svennson L, van Duijnhoven Y, Koopmans M (2004) Increase in viral gastroenteritis outbreaks in Europe and epidemic spread of new norovirus variant. Lancet 363(9410): 682-688

3. van den Hof S, van der Kooi T, van den Berg R, Kuijper EJ, Notermans DW (2006) Clostridium difficile PCR ribotype 027 outbreaks in the Netherlands: recent surveillance data indicate that outbreaks are not easily controlled but interhospital transmission is limited. Euro Surveill 11(1):E060126.2

4. Kuijper EJ, Coignard B, Tüll P (2006) Emergence of Clostridium difficile-associated disease in North America and Europe. Clin Microbiol Infect 12(Suppl 6):2-18

5. Kuijper EJ, van den Berg RJ, Debast S, Visser CE, Veenendaal D, Troelstra A, van der Kooi T, van den Hof S, Notermans DW (2006) Clostridium difficile ribotype 027, toxinotype III, the Netherlands. Emerg Infect Dis 12(5):827-830

6. Notermans DW, van der Kooi TII, Goorhuis A, Debast SB, van Benthem BHB, Kuijper EJ (2008) De epidemiologie van Clostridium difficile PCR-ribotype 027 in Nederland sinds 2005 en de opkomst van andere typen. Ned Tijdschr Geneeskd 152(35):1937-1940

7. Levy DG, Stergachis A, McFarland LV, Van Vorst K, Graham DJ, Johnson ES, Park BJ, Shatin D, Clouse JC, Elmer GW (2000) Antibiotics and Clostridium difficile diarrhea in the ambulatory care setting. Clin Ther 22(1):91-102

8. Hirschhorn LR, Trnka Y, Onderdonk A, Lee ML, Platt R (1994) Epidemiology of community-acquired Clostridium difficile-associated diarrhea. J Infect Dis 169(1):127-133

9. Centers for Disease Control and Prevention (CDC) (2005) Severe Clostridium difficile-associated disease in populations previously at low risk - four states, 2005. MMWR Morb Mortal Wkly Rep 54 (47):1201-1205

10. Siebenga JJ, Vennema H, Duizer E, Koopmans MP (2007) Gastroenteritis caused by norovirus GGII.4, The Netherlands, 1994-2005. Emerg Infect Dis 13(1):144-146

11. Wilcox M, Fawley W (2007) Viral gastroenteritis increases the reports of Clostridium difficile infection. J Hosp Infect 66(4):395-396

12. Bignardi GE, Staples K, Majmudar N (2007) A case of norovirus and Clostridium difficile infection: casual or causal relationship? J Hosp Infect 67(2):198-200

13. Barrett SP, Holmes AH, Newsholme WA, Richards M (2007) Increased detection of Clostridium difficile during a norovirus outbreak. J Hosp Infect 66(4):394-395

14. van den Berg RJ, Vaessen N, Endtz HP, Schülin T, van der Vorm ER, Kuijper EJ (2007) Evaluation of real-time PCR and conventional diagnostic methods for the detection of Clostridium difficile-associated diarrhoea in a prospective multicentre study. $\mathrm{J}$ Med Microbiol 56(Pt 1):36-42

15. Zheng L, Citron DM, Genheimer CW, Sigmon SF, Carman RJ, Lyerly DM, Goldstein EJ (2007) Molecular characterization and antimicrobial susceptibilities of extra-intestinal Clostridium difficile isolates. Anaerobe 13(3-4):114-120
16. van den Berg RJ, Ameen HA, Furusawa T, Claas EC, van der Vorm ER, Kuijper EJ (2005) Coexistence of multiple PCRribotype strains of Clostridium difficile in faecal samples limits epidemiological studies. J Med Microbiol 54(Pt 2):173-179

17. Bidet P, Barbut F, Lalande V, Burghoffer B, Petit JC (1999) Development of a new PCR-ribotyping method for Clostridium difficile based on ribosomal RNA gene sequencing. FEMS Microbiol Lett 175(2):261-266

18. Kato H, Kato N, Watanabe K, Iwai N, Nakamura H, Yamamoto T, Suzuki K, Kim SM, Chong Y, Wasito EB (1998) Identification of toxin A-negative, toxin B-positive Clostridium difficile by PCR. J Clin Microbiol 36(8):2178-2182

19. Pille F, Martens A, Schouls LM, Peelman L, Gasthuys F, Schot CS, De Baere C, Desmet P, Vandenberghe F (2004) Detection of bacterial DNA in synovial fluid from horses with infectious synovitis. Res Vet Sci 77(3):189-195

20. van den Berg RJ, Kuijper EJ, van Coppenraet LE, Claas EC (2006) Rapid diagnosis of toxinogenic Clostridium difficile in faecal samples with internally controlled real-time PCR. Clin Microbiol Infect 12(2):184-186

21. Martin AJ, Collins CJ, Ruddy R, Drudy D, Hannan MM, Kyne L (2008) Simultaneous control of norovirus and Clostridium difficile outbreaks due to enhanced infection prevention and control measures. J Hosp Infect 68(2):180-181

22. Freeman J, Wilcox MH (2003) The effects of storage conditions on viability of Clostridium difficile vegetative cells and spores and toxin activity in human faeces. J Clin Pathol 56(2):126-128

23. Borriello SP, Vale T, Brazier JS, Hyde S, Chippeck E (1992) Evaluation of a commercial enzyme immunoassay kit for the detection of Clostridium difficile toxin A. Eur J Clin Microbiol Infect Dis 11(4):360-363

24. Turcios RM, Widdowson MA, Sulka AC, Mead PS, Glass RI (2006) Reevaluation of epidemiological criteria for identifying outbreaks of acute gastroenteritis due to norovirus: United States, 1998-2000. Clin Infect Dis 42(7):964-969

25. Bartlett JG (2008) Historical perspectives on studies of Clostridium difficile and $C$. difficile infection. Clin Infect Dis 46(Suppl 1):S4-S11

26. Woo PC, Lau SK, Chan KM, Fung AM, Tang BS, Yuen KY (2005) Clostridium bacteraemia characterised by $16 \mathrm{~S}$ ribosomal RNA gene sequencing. J Clin Pathol 58(3):301-307

27. Steer T, Collins MD, Gibson GR, Hippe H, Lawson PA (2001) Clostridium hathewayi sp. nov., from human faeces. Syst Appl Microbiol 24(3):353-357

28. Kikuchi E, Miyamoto Y, Narushima S, Itoh K (2002) Design of species-specific primers to identify 13 species of Clostridium harbored in human intestinal tracts. Microbiol Immunol 46(5):353358

29. Harvey SM, Sturgeon J, Dassey DE (2002) Botulism due to Clostridium baratii type F toxin. J Clin Microbiol 40(6):2260-2262

30. Fenicia L, Anniballi F, Aureli P (2007) Intestinal toxemia botulism in Italy, 1984-2005. Eur J Clin Microbiol Infect Dis 26 (6):385-394

31. Asha NJ, Tompkins D, Wilcox MH (2006) Comparative analysis of prevalence, risk factors, and molecular epidemiology of antibiotic-associated diarrhea due to Clostridium difficile, Clostridium perfringens, and Staphylococcus aureus. J Clin Microbiol 44(8):2785-2791

32. Crobach MJ, Dekkers OM, Wilcox MH, Kuijper EJ (2009) European Society of Clinical Microbiology and Infectious Diseases (ESCMID): data review and recommendations for diagnosing Clostridium difficile-infection (CDI). Clin Microbiol Infect 15(12):1053-1066 